\title{
Thinking in 3D: a future for dialysis?
}

\author{
Giorgina Barbara Piccoli ${ }^{1,2}$
}

Received: 16 July 2018 / Accepted: 23 July 2018 / Published online: 31 July 2018

(c) Italian Society of Nephrology 2018

\begin{abstract}
A recent paper, entitled "Validation of an effective, low cost, free/open access 3D-printed stethoscope", recently appeared on PLoS One, reports on the validation of a 3D-printed stethoscope that costs about 100 times less than the classic Littman most of us carry in our pockets. The stethoscope model, called Glia, can be downloaded for free. This unusual paper may deepened our understanding of inequalities in health care around the world, but may also show how much we can learn from the inventive approaches employed by colleagues struggling to provide health care when they literally have nothing. Teaching students to monitor heart auscultation with an inexpensive, well-functioning 3D-printed stethoscope can be a lesson in creating a better world. Furthermore, the article reminds that good research can be done without sponsorship. The study design is clear; the methods are reproducible; validation is up to us. At a time in which we may have to re-think our complex relationship with the medical industry, this paper underlines the importance of intellectual independence. Will the 3D-printer bring a wind of innovation to our practice? Will it contribute to the development of low-cost artificial kidneys? These are good questions, still without answers. For now, we might limit to one first, basic question: are we ready for 3D thinking?
\end{abstract}

Keywords Technology $\cdot$ Ecology $\cdot$ Cost $\cdot$ Health care

On my return from a meeting in Casablanca, where I had participated in an interesting exchange with the lively nephrology community working in Africa, and spent an evening hearing about the economic and logistic difficulties of expanding CKD care and dialysis in sub-Saharan countries, I found an email from David (Panda) Mery, one of the most innovative thinkers I have yet to meet [1].

Interested in reusing, recycling and giving new life to objects that would otherwise be discarded, Mery, who volunteers with the Restart Project (whose slogan is "Don't Despair, Just Repair"), is a precious ally, a hunter of novelties that impact on the medical field. This time he had written to draw my attention to a podcast and a paper that merit being shared with a wide public $[2,3]$.

The paper, entitled "Validation of an effective, low cost, free/open access 3D-printed stethoscope", recently appeared on the website PLoS One [2]. It reports on the validation

Giorgina Barbara Piccoli

gbpiccoli@yahoo.it

1 Nephrology, Centre Hospitalier Le Mans, Avenue Roubillard 194, 72000 Le Mans, France

2 Dipartimento di Scienze Cliniche e Biologiche, Università di Torino, Torino, Italy of a 3D-printed stethoscope that costs all of US\$ 2.83 to make, but has the same features as the Littman Cardiology III, that costs about 100 times as much. The Glia Model (which comes in some cute fluorescent shades the Littman model is not available in) is free: all the printed designs can be downloaded and are ready to use.

The paper takes a few minutes to read. It is time well spent.

I found it deepened my understanding of inequalities in health care around the world. To my shame, listening to the radio interview with the contact author, and talking with my Moroccan friends, I had to admit I had not thought enough about the enormous gap that exists between highly- and poorly-resourced countries. Social issues are implicit in the paper, and overtly declared in the podcast. Aside from what we learn about the impressive difficulties hospitals in Gaza have to overcome, the paper shows how much those of us who lead quiet lives can learn from the inventive approaches employed by colleagues struggling to provide health care when they literally have nothing. Making things is not only a way to health, but also, as the author says in his interview, a way to freedom. Teaching students to monitor heart bruits with an inexpensive, well-functioning 3D-printed stethoscope can be a lesson in creating a better world. 
The second reason I recommend reading the article is that it show good research can be done without sponsorship. The study design is clear; the methods are reproducible enough to give readers all the instructions they need to print and test their own 3D stethoscope; validation, according to the authors, is simple and can easily be reproduced. After reading the authors' complex declaration section stating that they have no competing interests, we understand that they not only carried out the study, but were also responsible for the production and dissemination of their product, and that they did not do this for money; as Churchill said in his speech after the battle of Normandy, they were fighting not for glory, but for freedom.

In addition, the study shows it is time we re-think our complex relationship with the medical industry, which often makes us see the tools we use (machines, supplies, etc) as necessities, something we have no power to change. When, for example, we realized the enormous quantity of plastic waste dialysis generates and asked to be allowed to shorten blood lines by $10 \mathrm{~cm}$ or employ reusable bicarbonate charts, the answer was, "Nice idea, it won't work. Forget it" [4].

The paper shows that this is not necessarily true.

Will the 3D-printer bring a wind of innovation to our practice? Will it help save the lives of CKD patients? Will it contribute to the development of low-cost artificial kidneys?
Will it improve our daily practice? These are good questions, and it is likely that it will be a while before they are answered. There is one question, however, that we can answer immediately: are we ready for 3D thinking?

Funding No fund was obtained for this editorial.

\section{Compliance with ethical standards}

Conflict of interest The author states that there is no conflict of interest.

Ethical approval This article does not contain any studies with human participants or animals performed by any of the authors.

\section{References}

1. https://gizmonaut.net. Accessed 10 May 2018

2. Pavlosky A, Glauche J, Chambers S, Al-Alawi M, Yanev K, Loubani T (2018) Validation of an effective, low cost, free/open access 3D-printed stethoscope. PLoS One 13(3):e0193087

3. https://soundcloud.com/restart-project-1/restart-radio-3d-print ing-medical-devices

4. Piccoli GB, Mery D (2017) Sister earth, our common home: toward a sustainable, planet friendly approach to dialysis, a paradigm of high technology medicine. J Ren Nutr 27(6):478-484 